\title{
Documentation Status and Self-Rated Physical Health Among Latinx Young Adult Immigrants: the Mediating Roles of Immigration and Healthcare Stress
}

\author{
Allison McCord Stafford ${ }^{1}$ (1) - Aneri Tanna ${ }^{2} \cdot$ Karina Moreno Bueno ${ }^{2} \cdot$ Gabriela A. Nagy $^{1,3} \cdot$ Irene Crabtree Felsman ${ }^{1,4}$. \\ Scott de Marchi ${ }^{5} \cdot$ Rushina Cholera $^{6} \cdot$ Kate Evans $^{7} \cdot$ Eliazar Posada $^{8} \cdot$ Rosa Gonzalez-Guarda $^{1}$
}

Received: 11 November 2021 / Revised: 28 January 2022 / Accepted: 9 February 2022 / Published online: 17 February 2022

(c) W. Montague Cobb-NMA Health Institute 2022

\begin{abstract}
Previous research has demonstrated that undocumented Latinx immigrants in the USA report worse physical health outcomes than documented immigrants. Some studies suggest that immigration-related stress and healthcare related-stress may explain this relationship, but none have tested it empirically. The purpose of this study was to determine if immigration-related stress and healthcare-related stress in the USA explain the relationship between documentation status and physical health among Latinx immigrants in North Carolina. The conceptual model was tested utilizing baseline data from a longitudinal, observational, community-engaged research study of young adult (18-44 years) Latinx immigrants residing in North Carolina $(N=391)$. Structural equation modeling was used to determine relationships among documentation status, healthcare, and immigration stress in the past six months, and self-rated physical health. Goodness-of-fit measures indicated that data fit the model well $(R M S E A=.008 ; C F I=1.0 ; T L I=.999 ; S R M R=.02 ; C D=.157)$. Undocumented individuals were more likely to experience immigration stress than their documented counterparts $(\beta=-0.37, p<0.001)$. Both immigration stress $(\beta=-0.22, p<0.01)$ and healthcare stress $(\beta=-0.14, p<0.05)$ were negatively related to physical health. Additionally, immigration stress was positively related to healthcare stress $(\beta=0.72, p<0.001)$. Results demonstrate that documentation status is an important social determinant of health. Passage of inclusive immigration and healthcare policies may lessen the stress experienced by Latinx immigrants and subsequently improve physical health.
\end{abstract}

Keywords Hispanic American · Immigration $\cdot$ Stress $\cdot$ Health disparity

\section{Introduction}

Latinx ${ }^{1}$ immigrants compose the largest racial-ethnic minority group in the United States (US) [1]. As of 2019, 60 million people were of Latinx (i.e.., Latino, Latine, or Hispanic) ethnicity in the US [1], and around 19 million individuals were born outside of the US [2]. Of Latinx immigrants in the US, around 8 million are present in the US without lawful immigration status (i.e., undocumented immigrants) [2]. Due to internal migration from other southern states and the growth of agrobusiness, North Carolina (NC) has become a new destination for Latinx immigrants in the last few decades [3]. Latinx individuals

Allison McCord Stafford

allison.stafford@duke.edu

Extended author information available on the last page of the article now comprise the largest growing racial-ethnic minority group in NC and nearly a quarter identify as undocumented ${ }^{2}$ immigrants [4]. Latinx communities in NC are outpacing the growth of Latinx communities compared to the rest of the country ( $28.3 \%$ vs, $19.6 \%$ respectively), making $\mathrm{NC}$ an important geographical area for promoting health equity in this population [5].

\footnotetext{
1 We use the term "Latinx" throughout the paper to characterize participants. This is a gender inclusive term that encompasses individuals from Latin American backgrounds and is sometimes used synonymously with Latino/a, Latine, and Hispanic. Study participants often identified themselves as of their country of origin (e.g., Mexican).

${ }^{2}$ We utilize the term "documentation status" throughout the paper as it is primarily utilized in the scientific literature in this area to describe individuals who are not lawfully present in the United States. However, we recognize that in the legal field, the terms "unauthorized," "without lawful status," or "immigration status" is also used.
} 
Despite representing a significant segment of the population in the United States, Latinx individuals are disproportionately affected by poor social determinants of health that lead to health disparities [6]. Immigration status is one such determinant of health which further increases the vulnerability of individuals within the Latinx population, even in places with more immigrant-welcoming health policies [7]. Due to their legal status, undocumented immigrants represent one of the most vulnerable sub-groups of Latinx individuals in the US, and unfavorable social and economic conditions have resulted in undocumented immigrants having worse physical health outcomes than documented Latinx immigrants, including poorer self-rated health $(\mathrm{SRH})[8,9]$ and a higher prevalence of both hypertension $[8,10]$ and obesity [11]. The significance of these health disparities is further exacerbated by the "chilling effect"-a phenomenon in which individuals are less likely to use health services due to threats of legal sanctions or fear that their documentation status will be exposed to immigration officials; this fear and uncertainty impacts immigrant families regardless of their documentation status [12]. SRH is an important indicator of health given that it is predictive of health outcomes among general $[13,14]$ and immigrant populations [15] and is an independent predictor of morbidity [16] and mortality [17] even when accounting for other health indictors.

Several biopsychosocial factors may explain the relationship between documentation status and physical health outcomes of Latinx immigrants [18]. Immigration stress, or the stress that Latinx immigrants experience in navigating the US immigration system, can contribute to chronic activation of the biological stress response, leading to negative health consequences such as systemic inflammation and poor health outcomes [19]. Others hypothesize that the relationship between immigration status and physical health outcomes may be due to the underutilization of health services by undocumented immigrants [20-22], as they are ineligible for most forms of public health insurances in the US [23]. While a body of research exists documenting the relationship between documentation status and health outcomes of Latinx immigrants, there is a need to further investigate the mechanisms that explain this relationship. This study contributes to the literature through a focus on how documentation status impacts physical health outcomes among Latinx immigrants using data collected during a hostile sociopolitical climate in the US from 2018 to 2020.

\section{Immigration Context in the US and North Carolina}

Latinx immigrants' daily lives are shaped by the historical context of immigration in the US. In 1798, the Alien and Sedition Act was passed in the US. This immigration policy enhanced views of foreigners as national threats, restricted immigrant residency, and facilitated the process of deporting immigrants [24]. In the following centuries, geopolitical tensions and economic instability fostered greater hostility towards immigrants, resulting in implementation of immigration policies that restricted immigration from Asian and European countries [25]. The Immigration and Nationality Act of 1965 overturned the established quota system that favored western Europeans and transitioned to a system based on immigrants' skills and their relationships with people in the US, which still often favored privileged European immigrants [26]. In 1996, the Illegal Immigration Reform and Immigration Responsibility Act was passed which strengthened the enforcement of legal sanctions for undocumented immigrants and increased border control [27]. The Department of Homeland Security (DHS) was then created in 2002 which houses the Immigration and Customs Enforcement (ICE) agency [28].

The modern period of Latinx immigration to NC began in the 1970's after Congress passed the Immigration and Nationality Act in 1965, which created new pathways for migrants across Latin America to come to the U.S [29]. Latinx migration increased as people from Mexico and other Latin American countries moved to the Southeast for agricultural, manufacturing, and meat-processing jobs. Beginning in the 1980s, Latinx immigrants also came to North Carolina to escape civil wars, hurricanes in Central America, economic crises, and drug violence in Mexico. From 1990 to 2000, the Latinx population in NC grew faster than anywhere else in the country, increasing from $0.5 \%$ of the population to more than $9 \%$ of the population [29]. The Latinx population in $\mathrm{NC}$ has continued to grow more rapidly than in other areas of the country and now includes more than 1 million residents [5].

Anti-immigrant sentiments towards Latinx individuals traces back to the 1930s when Latinx youth were arrested at significantly higher rates than other racial and ethnic groups for minor infractions, sent to military-style penitentiaries for harsh punishment, and forced to undergo sterilization [30]. Moreover, in the 1970s, the White supremacist movement furthered anti-immigrant initiatives such as the development of the Ku Klux Klan Border Watch to target Latinx immigrants crossing the Southern US border [31]. In recent years, hostility towards Latinx immigrants has worsened related to anti-immigrant rhetoric and policy of the Trump administration [31].

Latinx immigrants in NC are further disadvantaged by state policies that contribute to fear of deportation and limit access to health insurance and other resources. Some counties in NC have adopted Sect. 287(g) agreements, which allow for local law enforcement to act on behalf of the federal ICE agency to facilitate the detention and deportation of non-citizens charged with violating immigration laws [22]. 
Fig. 1 Conceptual model adapted from Cabral and Cuevas [35] describing mediators of the relationship between documentation status and physical health outcomes

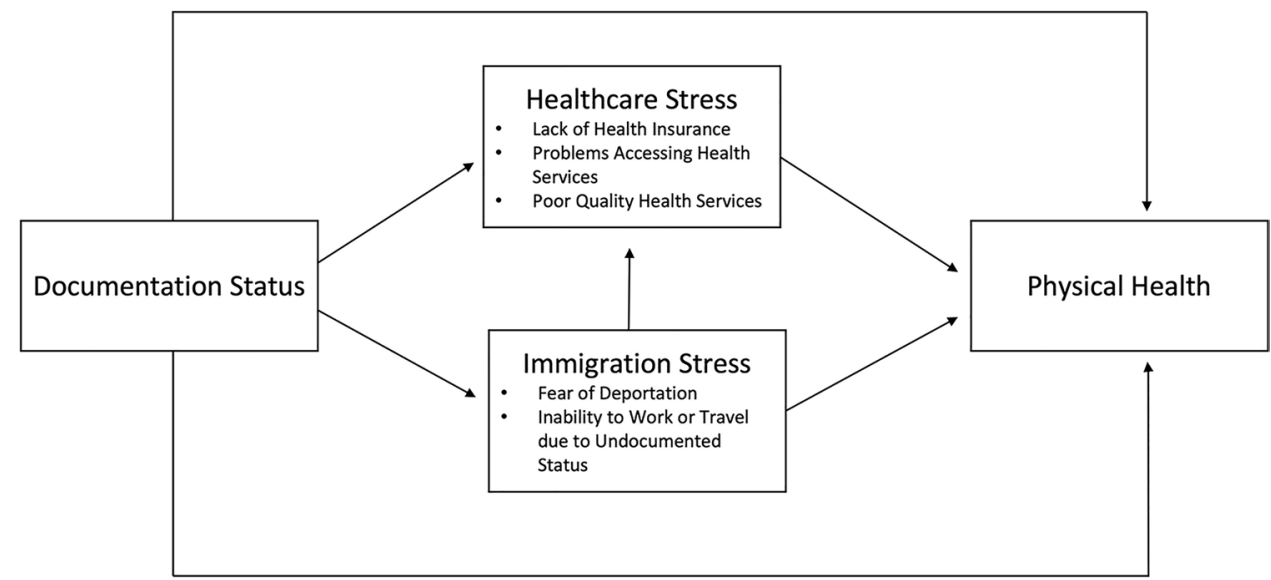

Access to health insurance in North Carolina is also largely dependent on one's documentation status [32]. Asylumseekers, people with Deferred Action for Childhood Arrival (DACA), Temporary Protected Status, or visas as victims of crimes are not eligible for Medicaid unless they are pregnant or under the age of 18 [32]. Additionally, state law restricts access to driver's licenses, professional licenses, in-state tuition, and financial aid for higher education based on documentation status [33]. DACA recipients do not qualify for in-state tuition or federal financial aid, and state law does not guarantee them eligibility for all state professional and occupational licenses [34]. The long history of anti-immigrant policy in the US has not only enacted structural barriers to resources for immigrants in the US but also has resulted in a hostile anti-immigrant climate contributing to Latinx immigrants' experiences of interpersonal racism.

\section{Conceptual Model}

Cabral and Cuevas [35] proposed a theoretical framework to explain the relationship between documentation status and health outcomes among Latinx individuals. They posited that three mechanisms distinctly affect undocumented Latinx immigrants and yield poor health outcomes: access to healthcare, access to health protective services, and immigrant enforcement actions. Access to healthcare, including ineligibility for Medicaid, proof of residency requirements, and physician implicit bias, may negatively impact undocumented immigrants and their health more so than their documented counterparts. Additionally, lack of access to healthprotective services can worsen health outcomes through restrictive federal, state, and local policies that limit undocumented immigrants' access to health-promoting resources such as state benefits and occupational protection policies. The third mechanism focuses on immigration enforcement actions as the mechanism through which documentation status impacts health outcomes. Immigration enforcement actions refer to local, state, and federal level law and policy which control the ability of individuals to enter and remain in the US. These actions spark confusion and fear within the immigrant community regarding documentation status, leading to psychological stress and the chronic activation of the biological stress response and later physical health consequences [36]. Additionally, immigration enforcement actions can indirectly impact physical health outcomes via inciting fear about seeking health services (i.e., the "chilling effect") [35]. These three mechanisms reinforce existing systemic barriers and inequities in the US healthcare and political system for undocumented Latinx immigrants. While some qualitative research has highlighted the lived experience of undocumented Latinx immigrants in the US [37, 38], these experiences have not been explored with hypothesis-driven questions that are informed by Cabral and Cuevas' framework.

Based on a review of current literature, we have tested an adaptation of Cabral and Cuevas' model to explain the mechanisms by which documentation status impacts physical health outcomes (see Fig. 1). The relationship between documentation status and physical health is explained via two distinct mediators-stress associated with accessing health services (i.e., healthcare stress) and stress associated with the immigration process (i.e., immigration stress). Healthcare stress is characterized by stress related to lack of health insurance, problems paying medical bills, and lack of quality health care, while immigration stress is defined as exposure to traumatic events during migration, fear of deportation, limited contact with family outside the US, and fear of family separation [39]. The model also accounts for immigration stress indirectly influencing physical health outcomes via healthcare stress because of the "chilling effect" as previously described. We propose a unidirectional relationship from immigration stress to healthcare stress to represent the impact of the chilling effect, whereby threats of deportation deter individuals from seeking healthcare and social services to which they may be entitled [12]. 


\section{Mediators of Relationship Between Documentation Status and Physical Health}

\section{Health Service Use}

One mechanism by which documentation status impacts physical health outcomes is via lack of access to health services. Current policies in many states have disadvantaged undocumented immigrants by limiting their access to health benefits [35], such as policies in NC that restrict access to Medicaid for undocumented immigrants. Consequently, only $54 \%$ of Latinx adults have health insurance compared with $75 \%$ nationally [5]. When compared to Non-Latinx whites, Latinx immigrants are also twice as likely to underutilize health care services and more likely to receive poor quality of care despite adjustments for federal poverty level, health insurance coverage, employment status, and health status [40]. Among Latinx adults in California, those who were undocumented were the least likely to see a doctor in the last 12 months (58\%) while US-born individuals were the most likely (78\%) [9]. Similarly, undocumented Mexicanborn immigrants have been found to have less utilization of health services compared to documented Mexican-born immigrants [41].

\section{Immigration Stress}

A second mechanism by which documentation status impacts physical health outcomes is via immigration stress. Restrictive immigration policies contribute to psychosocial stress experienced by undocumented individuals and their families [42] and may cause chronic activation of the biological stress response and subsequent health problems [36, 42]. Examples of restrictive policies enacted under the Trump Administration include the rescission of the Deferred Action for Childhood Arrivals (DACA) program [43], implementation of the "Zero Tolerance" Policy enforcing family separations and mass criminal prosecutions of immigrants at the US border [44], addition of government benefits considered under the Public Charge Rule [45], attempts to end Temporary Protected Status for immigrants from some Central and South American countries [46], and an increase in Immigration and Customs Enforcement (ICE) activity at the border and US interior [47]. In one study, household fear of deportation was associated with biomarkers of stress among both mixed- and non-mixed status ${ }^{3}$ Mexican-origin families [22]. Additionally, the aftermath of local immigration raids has been associated with low birth weight (LBW) in infants born

\footnotetext{
${ }^{3}$ Mixed status families are those in which some family members are undocumented, while others are documented immigrants or US-born citizens.
}

to documented, undocumented, and US-born Latina mothers [20], demonstrating the impact of immigration-related stress on physical health outcomes. Local immigration raids have also been linked to higher levels of immigration enforcement-related stress and lower SRH scores in Latinx immigrants compared to before the ICE raids [48].

\section{Relationship Between Immigration Stress and Healthcare Utilization}

Immigration stress may also indirectly affect health outcomes among immigrants via the "chilling effect," in which fear of immigration enforcement prevents immigrant families from seeking health services regardless of documentation status [12]. One policy that recently incited the "chilling effect" was the updated public charge rule, which aimed to designate people seeking certain types of temporary or permanent immigration status as public charges (i.e., unable to be self-sufficient) to the government if they have received non-cash government benefits (e.g., Supplemental Nutrition Assistance Program [SNAP], Medicaid for non-pregnant adults, Housing Assistance) [49]. While only a small portion of immigrants in the US was impacted by this update, which was in effect from October 2019 through March 2021, drafts of the updated public charge rule were leaked in 2017 and sparked fear and confusion about who would be impacted [49]. A recent study found that one in five adults in immigrant families with children reported avoiding public health benefits such as SNAP, Medicaid, Children's Health Insurance Program (CHIP), and housing subsidies in 2019 - an increase from one in seven in 2018 [50]. Additionally, Latinx immigrant adults were found to avoid public service programs at twice the rate, $21 \%$, compared to their non-Latinx counterparts at $9 \%$ as a response to the updated public charge rule [51]. These data suggest that the fear of triggering immigration consequences leads to an avoidance of public programs, even for benefits not included in the public charge rule $[50,52]$.

In addition to avoidance of government benefits, there is evidence that Latinx families have avoided seeking medical services due to fears of immigration enforcement. In Los Angeles (LA) County, adult undocumented immigrants reported that their underutilization of primary care services and enrollment in LA County health-social service programs was due to the fear of potential consequences of the updated public charge rule, such as losing eligibility for obtaining documentation status [52]. Across several studies, medical staff have also confirmed the decline of Latinx immigrant patients in health facilities compared to before the 2016 election [53-55], and one study found an increase in medical appointment cancellations for uninsured Latinx children after enaction of restrictive immigration policies by the Trump administration in early 2017 [56]. US-born 
children of undocumented immigrant mothers were also found to have a $17 \%$ higher rate of being uninsured compared to children with US-citizen mothers [57]. Although there are places where health services are provided to immigrants without lawful status, studies have shown that those localities are sometimes avoided due to a fear of presence of local police and ICE and fear of personal information being shared with ICE officers [10,58].

Local immigration enforcement has also been shown to have substantial impact on healthcare access and subsequent health outcomes of Latinx populations [22]. Local police and ICE surveillance, such as in Sect. 287(g) agreements, has debilitated mobility for undocumented Latinx individuals in seeking health services [6]. In NC, enactment of Sect. 287(g) agreements in certain counties has been associated with decreased and delayed prenatal care among Latinx women and influenced lower quality of care compared to counties without 287(g) agreements [59]. This was likely due to increased fear of deportation, discrimination, and mistrust of the healthcare system which were observed along with the enactment of the NC $287(\mathrm{~g})$ policy [59].

\section{The Current Study}

The rise of anti-immigrant rhetoric and policies has created toxic environments for Latinx individuals and promoted the marginalization of already vulnerable Latinx immigrant populations [20, 22, 48, 59]. Ultimately, this serves as a form of institutionalized racism that has produced clear health inequalities over the years in Latinx populations due to federal, state, and local levels of immigration policy enforcement [22]. However, there is a gap in the literature pertaining to the specific roles that healthcare stress and immigration stress play in explaining physical health disparities among undocumented Latinx immigrants, particularly within the current sociopolitical climate. The purpose of the current study was to further explicate these relationships. This information will be useful to policy stakeholders, community members, and healthcare providers to direct their advocacy efforts towards specific policy and enforcement actions that will ultimately have the greatest impact on Latinx health disparities.

Our primary aims were to investigate if individuals who are undocumented are more at risk for poor physical health than their documented peers because they experience stress in accessing health services and/or their experience of immigration stress. We have hypothesized the following relationships:

1) Healthcare stress will mediate the relationship between documentation status and SRH.
2) Immigration stress will mediate the relationship between documentation status and SRH.

3) There will be an additional indirect relationship between documentation status and SRH via the relationship between immigration stress on health service use.

\section{Methods}

The Salud (Health), Estrés (Stress), y Resiliencia (Resiliency) (SER) Hispano Study was a longitudinal, observational, community-engaged research study of young adult Latinx immigrants in NC. The study aimed to examine the relationships between acculturation stress, resiliency, and health outcomes among young adult Latinx immigrants in NC. The current analysis utilized baseline data from the participants in the SER Hispano Study $(N=391)$.

\section{Sample and Setting}

Participants were recruited using community-based recruitment strategies. We collaborated with a Latinx non-profit organization to embed community members in the research team from study planning to dissemination of results. To recruit participants, we placed ads in locations frequented by Latinx families and participated in community events (e.g., health fairs, cultural events). To be eligible for the study, participants had to meet the inclusion criteria of being a young adult between 18 and 44 years of age, identifying as Latinx or Hispanic, residing in the US for 1 year or more, living within a 50-mile radius of Duke University, and having immigrated from a Latin American country to the US. Individuals were excluded from participating in the study if they had plans to move out of the Research Triangle (Durham-Raleigh-Chapel Hill area in NC) within the next 2 years. The team also kept in touch with participants by providing newsletters about study results, sending birthday cards, and distributing information and resources during the COVID-19 pandemic. Additionally, our research team held a yearly immigrant health conference for community members and researchers to share resources.

\section{Procedures}

Each participant was interviewed every 6 months for a period of 2 years, totaling 5 visits. At each visit, bilingual assessors with experience working in the local Latinx community interviewed the participants using approximately 270 structured, self-report questions. Participants did not need to be able to read or write; however, participants were given the choice to complete the questions themselves, if preferred. Data collection was conducted in Spanish or English based on the participant's preference. 
Furthermore, biological data of body mass index (BMI), blood pressure, and blood and urine samples (to analyze markers of inflammation and oxidative stress) were also collected from the participants at the end of each visit. These procedures were approved by the Duke University Health System Institutional Review Board, and all participants provided written informed consent prior to participating in the study. Participants were compensated $\$ 50$ for the baseline data collection visit.

\section{Measures}

\section{Independent Variable}

To allay concerns about the nature of our research study, participants were not asked directly about their documentation status. Instead, we derived our documentation status variable from a proximate measure based on health insurance coverage, which has commonly been employed to assess documentation status in studies of immigrant health [60]. Participants who reported no insurance coverage were asked, "What is the reason for not having health insurance?" Participants had the option of choosing "Documentation Status," "Lack of Knowledge," or "Not Provided and Can't Afford" as responses. Participants who reported no health insurance coverage and chose the response "Documentation Status" were classified as undocumented immigrants. Participants who reported health insurance coverage or who reported no health insurance but chose reasons other than "Documentation Status" for lack of coverage were categorized as documented immigrants.

\section{Mediators}

The Healthcare Stress and Immigration Stress Appraisal Subscales from the Hispanic Stress Inventory-2 [39] were used in the current analysis. The Hispanic Stress Inventory-2 (HSI-2) is a valid and reliable measure consisting of 90 items that assess different sources of acculturative stressors in the past six months and asks participants to appraise their stress level arising from these stressors. The Healthcare Stress Subscale consists of 8 items assessing for events such as difficulties paying for or accessing high-quality medical care with scores ranging from 0 to 40 and demonstrated good internal consistency reliability in the current sample $(\alpha=0.85)$. The Immigration Stress Subscale consists of 9 items and assesses for events such as fears of deportation and employment challenges linked to lack of lawful legal status with scores ranging from 0 to 45 [39]. This subscale also evidenced good internal consistency reliability in the current sample $(\alpha=0.85)$.

\section{Dependent Variable}

Self-reported physical health was our outcome of interest. This was assessed using the Physical Health Subscale of the Patient-Reported Outcomes Measurement Information System-10 (PROMIS-10) Global Health [61]. The Physical Health Subscale of PROMIS-10 Global Health instrument consists of 4 items assessing self-reported general physical health, pain, fatigue, and ability to complete activities of daily living in the past week. Scores ranged from 4 to 20 with lower scores indicating better health. The measure evidenced poor reliability in the current sample $(\alpha=0.52)$. However, we also ran analyses with a one-item SRH measure and reached the same results.

\section{Covariates}

We also controlled for demographic variables such as age, gender, and the highest level of education. We relied on employment status as a measure of socioeconomic status rather than income due to substantial missingness in the income variable. Additionally, we measured language enculturation (i.e., Spanish language use), social support (i.e., familism), and global mental health. We measured acculturation with the 12-item Hispanicism scale of the Bidimensional Acculturation Scale [62], which measures frequency of media use, language use, and social activities in Spanish. Social support was measured with 15-item Familism Scale [63] since research has shown that social support is protective against physical health problems among general populations [64], and familism, or family closeness and affiliation, is particularly protective against physical health problems among the Latinx population [65]. The 4-item mental health subscale from the PROMIS-10 was used to measure global mental health [61], given the body of literature documenting relationships between physical and mental health outcomes [66].

\section{Data Analysis}

Descriptive statistics and regression analyses were performed using Stata 16.1 (StataCorp) and R 3.6.1 (R Foundation for Statistical Computing). Our analyses include both a regression-based approach and a structural equation model (SEM). For both the regression model and the SEM, the primary outcome variable was the respondent's PROMIS 
Fig. 2 Structural equation model. The partial mediating roles of healthcare and immigration stress on the relationships between documentation status and self-rated physical health. All pathways are standardized coefficients. $* p<0.05$, $* * p<0.01, * * * p<0.001$

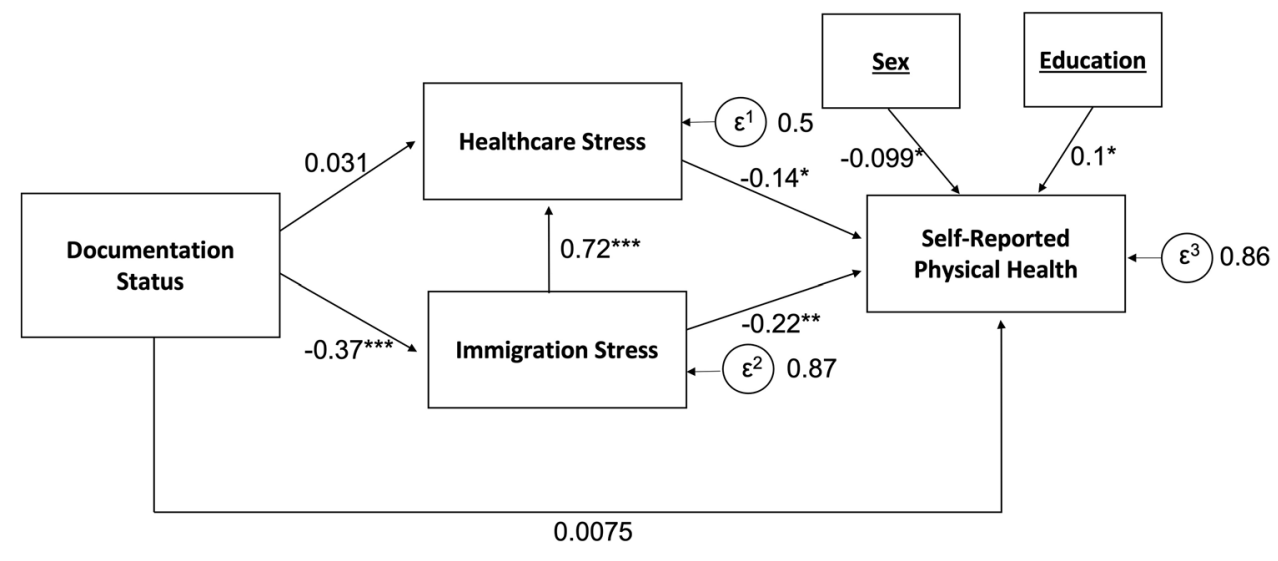

physical health score (phealth). An alternative outcome variable we explored was a one-item self-reported measure of health. Results for this variable were nearly identical, with the exception that the role of immigration stress was attenuated in the alternative model. Our theoretical focus was on the effects of documentation status, healthcare stress, and immigration stress on this outcome variable. We relied on a set of covariates describing length of time in the US, sex at birth, employment status, education, age, and a measure of familism.

For the regression, we relied on a regularized regression using the lasso to identify independent variables that have reliable effects out-of-sample. The purpose of this model was to examine the main effects for documentation status, health stress, and immigration stress and test to see if these effects hold out-of-sample using the following model:

health $\sim f$ (years in US, sex at birth, employment status, years of education, age, familism, health stress, immigration stress, documented $)+e \sim N(0, \mathrm{~s} 2) e \sim N(0, \mathrm{~s} 2)$.

Additionally, we used this model to trim the space of covariates included in the SEM model (see Fig. 2). We relied on a linear regression model using k-fold crossvalidation $(k=5)$ and the lasso (with lambda to minimize cross-validated error; Hastie \& Qian, 2016). We initially included Hispanicism and the mental health subscale of the PROMIS-10 in the list of covariates. However, due to multicollinearity with years in the US and stress variables, we made the decision to omit these variables from further analysis. For the SEM, we estimated a linear model using maximum likelihood estimation. We evaluated model fit using the comparative fit index $(C F I)$, the root mean square error of approximation (RMSEA), and TuckerLewis index $(T L I)$.

As an additional check on the validity of our approach, we examined whether the measures for healthcare and immigration stress were distinct from other types of stress measured in the survey (i.e., parental, occupational, marital, marital acculturation, discrimination, language, premigration, and family acculturative stress). A principal components analysis (PCA) of the stress measures had only two components with eigenvalues greater than one; together these components explained $56 \%$ of the total variance which is a poor fit to the data. Examination of a scree plot supported the choice of a two-component model. For the two stress measures of interest-healthcare and immigration-37\% and $47 \%$ of their variance respectively were unexplained by the PCA. Given these findings, we included the measures of stress directly and did not depend on a latent model of stress.

\section{Results}

Our sample includes a total of 391 respondents and is described in Table 1. For documented respondents, the mean age was 33.47 years, $66 \%$ of the population was female, $47 \%$ had health insurance, and $78 \%$ were employed. These respondents had a mean level of education of 12.27 years and had lived in the US a mean of 13.84 years. For undocumented respondents,

Table 1 Demographic characteristics of documented and undocumented respondents

\begin{tabular}{|c|c|c|c|c|}
\hline \multirow[t]{2}{*}{$\begin{array}{l}\text { Characteristic } \\
(N=391)\end{array}$} & \multicolumn{2}{|c|}{$\begin{array}{l}\text { Documented } \\
(n=258)\end{array}$} & \multicolumn{2}{|c|}{$\begin{array}{l}\text { Undocumented } \\
(n=133)\end{array}$} \\
\hline & Mean & Std. dev & Mean & Std. dev \\
\hline Age (years) & 33.47 & 7.27 & 34.62 & 6.23 \\
\hline Sex at birth $(0=$ male, $1=$ female $)$ & 0.66 & 0.48 & 0.75 & 0.43 \\
\hline Years of education & 12.27 & 3.96 & 9.87 & 3.61 \\
\hline Health insurance $(0=$ no, $1=$ yes $)$ & 0.47 & 0.50 & 0.00 & 0.00 \\
\hline Employment status & 0.78 & 0.41 & 0.66 & 0.48 \\
\hline Years lived in US & 13.84 & 7.57 & 12.83 & 5.91 \\
\hline Immigration stress & 14.53 & 7.19 & 21.01 & 9.03 \\
\hline Healthcare stress & 12.05 & 5.90 & 15.34 & 7.89 \\
\hline Self-rated physical health & 14.50 & 2.50 & 13.62 & 2.85 \\
\hline
\end{tabular}


Table 2 Regularized regression model of predictor variables on selfrated physical health

\begin{tabular}{lrlrlr}
\hline $\begin{array}{l}\text { Predictor } \\
(N=380)\end{array}$ & \multicolumn{1}{l}{$S E$} & \multicolumn{1}{l}{$t$} & $p$ & \multicolumn{1}{l}{ Beta } \\
\hline Documentation status & 0.044 & 0.303 & 0.140 & 0.885 & 0.008 \\
Years in the US & -0.005 & 0.016 & -0.230 & 0.818 & -0.012 \\
Sex at birth & -0.556 & 0.293 & -1.900 & 0.058 & -0.096 \\
Employment & 0.022 & 0.319 & 0.070 & 0.945 & 0.003 \\
Years of education & 0.054 & 0.035 & 1.550 & 0.123 & 0.081 \\
Age & -0.016 & 0.016 & -0.850 & 0.397 & -0.043 \\
Familism & -0.160 & 0.291 & -0.550 & 0.582 & -0.027 \\
Health stress & -0.051 & 0.027 & -1.880 & 0.06 & -0.131 \\
Immigration stress & -0.068 & 0.023 & -3.000 & 0.003 & -0.218 \\
\hline
\end{tabular}

baseline model $=4.09 / 386.38 ; R M S E A=0.008 ; C F I=1.0$; $T L I=0.999 ; S R M R=0.02 ; C D=0.157)$. These measures indicated that the model was a good fit to the data and that the relationships conformed to the hypotheses. This model demonstrated that documentation status was mediated by immigration stress, which in turn predicted SRH as posited by our theoretical model. More specifically, documentation status and SRH were indirectly related through the effect of immigration stress and healthcare stress on SRH (see Table 3). Documentation status was negatively related to immigration stress $(\beta=-0.37, p<0.001)$, and both immigration $(\beta=-0.22, p<0.01)$ and healthcare stress $(\beta$ $=-0.14, p<0.05)$ were negatively related to SRH. Immigration stress and healthcare stress were also positively related to each other $(B=0.72, p<0.001)$. Female sex $(\beta=-0.099$,
Table 3 Total, direct, and indirect effects in the structural equation model

\begin{tabular}{llll}
\hline $\begin{array}{l}\text { Pathways in structural equation model } \\
(N=380)\end{array}$ & Total effect & Direct effect & Indirect effect \\
\hline $\begin{array}{l}\text { Doc. status }->\text { stress }->\text { self-rate physical health } \\
\text { Doc. status }->\text { self-rated physical health }\end{array}$ & $0.659 *$ & \\
$\begin{array}{l}\text { Doc. status }->\text { Imm. stress }->\text { health stress } \longrightarrow>\text { self- } \\
\text { rated physical health }\end{array}$ & & 0.042 & $0.617 * * *$ \\
\hline$* p<0.05, * * p<0.01, * * * p<0.001$. & & \\
\hline
\end{tabular}

the subsample was similar but included a higher proportion of females and was less educated.

\section{Regression Model}

Table 2 shows results for the linear regression model that represents a limited version of the theoretical model. ${ }^{4}$ As expected, both health stress $(B=-0.051, p=0.06)$ and immigration stress $(B=-0.068, p=0.003)$ were associated with poorer SRH; the only other major effects were from education $(B=0.054, p=0.12)$, which is associated with improved health, and sex at birth $(B=-0.56, p=0.058)$, which was associated with poorer SRH for female respondents. Given the relatively small sample size, we also ran a regularized regression. All variables were retained with identical signs and magnitudes, adding support to our findings. ${ }^{5}$

\section{SEM Model}

In Fig. 2, the path coefficients are displayed for the theoretically derived SEM model. Goodness-of-fit measures supported the model $\left(\chi^{2}\right.$ against saturated and

\footnotetext{
${ }^{4}$ The dependent variable for overall health is integer but approximately normally distributed.

5 The elastic net is a penalized maximum likelihood model [77]. Our models have an elastic net penalty with alpha set to 1.0 , which is known as the lasso. Results were generated using k-fold cross validation and the value for lambda that maximized model fit out of sample.
}

$p<0.05)$ and years of education $(\beta=0.1, \mathrm{p}<0.05)$ were also associated with SRH in the model.

\section{Discussion}

The purpose of our study was to elucidate the mechanisms by which documentation status is related to self-rated physical health among Latinx immigrants as previous research has demonstrated that undocumented individuals are more likely to report worse physical health than documented immigrants $[8,9]$. We sought to develop an understanding of why this relationship exists to inform public health and policy efforts aimed at improving the health of Latinx immigrants in the US. Our paper adds to the literature documenting the relationship between documentation status and SRH, and to our knowledge, is the first to test an adapted version of Cabral and Cuevas' [35] model to determine the mechanisms by which documentation status impacts SRH outcomes among Latinx immigrants.

Our findings support our hypothesis that undocumented individuals are more likely to experience worse self-reported physical health than documented individuals. This finding bolsters the literature examining documentation status and physical health outcomes. Our findings are consistent with other studies that found that undocumented individuals were more likely to report poor physical health than documented individuals $[8,9]$. However, our findings are discordant with 
some literature documenting no significant relationships or positive relationships between documentation status and objective measures of physical health. For example, others have found that undocumented individuals were less likely to be obese than documented immigrants $[9,11]$ and not any more likely to report poor SRH [67] or worse diabetes outcomes [68] than documented immigrants. Discrepancies in these findings may be attributed to the age of the sample (i.e., more variation in physical health outcomes with older samples), a variety of health outcomes being examined (e.g., diabetes v. SRH v. body mass index), lack of controlling for relevant covariates (e.g., years in the US) [8], or different levels of exposure to immigration stress across a variety of geographic areas. Future research should include both objective and subjective measures of physical health to better elucidate the relationship between documentation status and physical health outcomes of Latinx immigrants, with the recognition that SRH is still a powerful indicator of future morbidity [16] and mortality [17] even among young adults [69].

In our study, we also found that the impact of documentation status on self-rated physical health was predominately explained by the indirect effect of immigration stress, a modest but significant effect. Our results demonstrated that undocumented individuals were more likely to experience immigration stress, and greater immigration stress corresponded to poorer physical health. This research bolsters the limited pre-existing literature examining the effects of immigration stress on physical health outcomes [67]. Our findings suggest that immigration stress negatively impacts health outcomes in a manner similar to discrimination stress in Latinx immigrants as described in the literature. Discrimination stress has been found to correspond to poorer SRH as well as stress biomarkers [37, 70]. Exposure to chronic psychological stressors among racial and ethnic minority groups stimulates the biological stress response that, consequently, produces health disparities among these populations [36]. Immigration enforcement on the local, state, and federal levels incites such stress through confusion and fear within immigrant communities, consequently harming their physical health as demonstrated by impacts of immigration raids on birth outcomes [20] and SRH among Latinx immigrants [48]. Our research highlights the detrimental effects of a hostile immigration climate on the health and well-being of Latinx immigrants, particularly those without legal status.

Our results also demonstrated a strong, significant relationship between immigration stress and healthcare stress in Latinx immigrants, which is consistent with the "chilling effect." The results support that immigration stress stemming from, but not limited to, fear of deportation, lacking documentation status, or not having the ability to legally drive, is related to healthcare stressors such as accessing quality healthcare, paying for healthcare services, facing language barriers in healthcare facilities, and more. This finding adds to the current literature noting that undocumented immigrants have less healthcare access and underutilization of healthcare services because of fear of deportation, particularly in the context of the unstable immigration climate in recent years. For example, Toomey and colleagues [21] found that the Arizona immigration policy, Senate Bill 1070 (S.B. 1070), increased fear of deportation among immigrants and led to decreased utilization of healthcare services such as prenatal care, pediatric care, and adult care. There is growing literature that has reported how various restrictive federal, state, and local health and immigration policies have had adverse health implications on health service-seeking behaviors within the undocumented Latinx immigrant population including decreased utilization of public benefits in undocumented and mixed-status families due to the Public Charge rule, decline of Latinx immigrant patients in health facilities after the 2016 election, decreased utilization of prenatal and pediatric care following S.B. 1070, and impact of Sect. 287(g) agreements on uptake of prenatal care [21, $50,51,53-56,59]$. When coupling a restrictive immigrant environment with public charge policy updates and the fact that undocumented immigrants are ineligible for most public health services, the decrease in health services use becomes exacerbated, thereby reinforcing existing systemic barriers and inequities in the US healthcare system for undocumented Latinx immigrants. Given the last administration's perpetuation of a climate that excluded immigrants, it is crucial to repair the negative impacts of this climate on the health outcomes of not only undocumented Latinx immigrants, but also mixed-status families.

Finally, our results demonstrated that being female and having lower levels of education were associated with worse SRH independent of the effects of other variables. These findings are consistent with previous research among general and immigrant-specific US populations [71, 72]. For example, Bacong et al. found that being male and having higher levels of education was associated with better SRH [72]. Sex differences in SRH are also more prominent earlier in life than in older adulthood $[71,73]$ which may also explain the significant findings in our sample of young adults. Women may also be more less likely to bring in significant income and are often expected to take on more caregiving responsibilities than men, leading to cumulative emotional and physical burdens throughout their lives that can negatively impact health [73].

\section{Limitations}

These findings should be interpreted within the context of the limitations of our study. First, we used a proximate measure of documentation status to determine which participants were "documented" or "undocumented" because individuals in the parent study were not directly asked about their documentation status. Since undocumented individuals were 
identified through their response to the reason for not having health insurance, we may have misclassified some undocumented immigrants as documented if they did report having health insurance. This misclassification bias may likely underestimate the relationships observed in our study. Additionally, documentation status is not binary. People seeking asylum, for example, may eventually be able to access work authorization while awaiting a decision on their application but have no formal temporary or permanent immigration status in the US. Likewise, individuals with DACA can work and obtain driver's licenses but cannot participate in the healthcare exchanges to access insurance benefits under the Affordable Care Act. A person with work authorization, even without formal immigration status, may experience less immigration stress than a person without any authorization. Conversely, their status is much less secure than a person with permanent lawful status (i.e., green card), and thus, their immigration stress may be significantly greater. Our sample was also comprised solely of young adults, and therefore, we may not have observed the same variability in self-rated physical health as we would have seen with a more age-diverse sample. Additionally, we used crosssectional baseline data from the parent study, and therefore cannot infer causation from our mediational model. Future research should address these limitations by longitudinally examining the relationships between documentation status, healthcare and immigration stress, and both subjective and objective measures of physical health outcomes, using precise measures of documentation status among a diverse sample of Latinx immigrants from states across the US. Future research might also incorporate measures of a variety of social drivers of health (e.g., neighborhood level resources and safety, economic opportunities, and policies) that may differentially impact immigrants' SRH.

\section{Implications}

Our findings have implications for both immigration and health policy. For example, current federal legislative proposals to create pathways to long-term lawful status for millions of essential workers and people with temporary protected status or DACA could result in large-scale improvements in SRH. The study also indicates that increases in SRH could be achieved without action by Congress. Eliminating the restrictions in the Public Charge Rule under the Trump administration, and publicizing that change broadly, could alleviate some degree of immigration stress. Separating state and local law enforcement agencies from immigration enforcement and ending immigration enforcement actions (e.g., raids) in communities would reduce uncertainty and day-to-day fear and could therefore lead to improved SRH.
Restrictive immigration policies such as expanding the list of programs considered under the public charge rule in 2019 have led many immigrants without lawful status or those in mixed-status families to avoid participation in government safety-net programs such as Medicaid, the Children's Health Insurance Program, or SNAP. While the changes to the public charge rule were rescinded in March 2021, the chilling effect remains, with many immigrant families continuing to avoid needed health care and other services during the COVID-19 pandemic. Publicizing the changes to the rule to ensure families access benefits they are eligible for is vital and will take time. Additionally, advocating simultaneously for comprehensive policy change to revise the public charge rule as a whole and moving towards more inclusive policies such as access to health care regardless of lawful status has the potential to improve the health of immigrant families long-term.

These findings point to the conclusion that within the large population of Latinx immigrants residing in the US, those who are undocumented may be more vulnerable to health declines. Therefore, health care providers are encouraged to assess, in the context of a safe therapeutic relationship, the extent to which social stressors (such as being undocumented or experiencing immigration stress) are relevant for their patients and are affecting their health. In cases where patients report these are especially relevant to the presenting problem, health care providers are encouraged to assist patients in finding ways to either reduce those stressors (e.g., connecting to a social worker) and/or increase resilience (i.e., coping strategies to buffer against those stressors). Furthermore, these findings are also relevant for intervention developers as reducing these sources of stress can represent malleable targets for intervention that ought to be considered novel interventions to support the health of Latinx immigrants.

Additionally, given that this sample lacked health insurance, it is important to embed these clinical approaches in health care facilities that are more frequently accessed by Latinx immigrants such as community clinics (e.g., federally qualified health centers) and emergency departments [23, 74]. These safety net systems, which are scarcer in recent immigrant destinations, such as where this study was carried out [75], need to be designed to be inclusive of Latinx immigrants. If these facilities are not designed appropriately (e.g., culturally and linguistically appropriate care; low-cost options for uninsured populations), they may further exacerbate acculturative stress and health disparities in this population.

\section{Conclusion}

The Latinx population experiences health inequities in the US, and these inequities vary according to the myriad factors that contribute to the diversity of this population. In the 
current study, we sought to understand how one facet of this diversity, documentation status, impacts SRH among Latinx young adults in a new immigrant destination during a hostile sociopolitical climate. This relationship was indirectly explained via immigration and healthcare stress, indicating that immigration and healthcare policy efforts to mitigate these stressors would likely have an impact on physical health inequities experienced by undocumented Latinx immigrants.

Author Contribution All authors contributed to the study conception and design. Data analysis was performed by Scott de Marchi. Allison Stafford, Aneri Tanna, and Karina Moreno Bueno drafted the first version of the manuscript, and all authors commented on previous versions of the manuscript and provided substantial input. All authors read and approved the final manuscript.

Funding Research reported in this publication was supported by the National Institute on Minority Health and Health Disparities of the National Institutes of Health under Award Number R01MD012249 and a Bass Connections grant from Duke University. Dr. Gabriela A. Nagy is supported by a Diversity Supplement from the National Institute on Minority Health and Health Disparities (R01MD01224903S1), an institutional Career Development Award through the Duke University REACH Equity Center funded through the National Institute on Minority Health and Health Disparities (5U54MD012530-04), the DISCO K12 Program through the Department of Population Health Sciences at Duke University funded through the National Heart, Lung, and Blood Institute (NHLBI) (5K12HL138030-05), and a fellowship with the Research in Implementation Science for Equity (RISE) at the University of California San Francisco's Center for Vulnerable Populations, through an award from the National Heart, Lung, and Blood Institute (5R25HL126146-07). The content is solely the responsibility of the authors and does not necessarily represent the official views of the National Institutes of Health or other funding bodies.

All study procedures were approved by the Duke University Health System Institutional Review Board (Protocol \#0008779), and all participants provided written informed consent prior to participating in the study.

\section{Declarations}

Competing Interests The authors declare no competing interests.

\section{References}

1. Noe-Bustamante L, Lopez MH, Krogstad JM 2020 U.S. Hispanic population surpassed 60 million in 2019, but growth has slowed. Pew Research Center. 2020. Available from: https://www.pewre search.org/fact-tank/2020/07/07/u-s-hispanic-population-surpa ssed-60-million-in-2019-but-growth-has-slowed/. Accessed 28 Oct 2021.

2. Batalova J, Hanna M, Levesque C 2021 Frequently requested statistics on immigrants and immigration in the United States. Migration Policy Institute. 2021. Available from: https://www. migrationpolicy.org/article/frequently-requested-statistics-immig rants-and-immigration-united-states-2020. Accessed 28 Oct 2021.

3. UNC Communications 2019 Q\&A: North Carolina's history of Latin American migration. UNC News. 2019. Available from: https://uncnews.unc.edu/2019/09/10/qa-north-carolinas-historyof-latin-american-migration/. Accessed 28 Oct 2021.

4. Fleming PJ, Villa-Torres L, Taboada A, Richards C, Barrington C. Marginalisation, discrimination, and the health of Latino immigrant day labourers in a central North Carolina community. Health Soc Care Community. 2017;25:527-37. https://doi.org/10.1111/ hsc. 12338 .

5. Ordoñez E 2020 North Carolina's Hispanic Community: 2020 snapshot. Carolina Demography. 2021. Available from: https:// www.ncdemography.org/2021/02/05/north-carolinas-hispaniccommunity-2020-snapshot/. Accessed 28 Oct 2021.

6. Ornelas IJ, Yamanis TJ, Ruiz RA. The health of undocumented Latinx immigrants: What we know and future directions. Annu Rev Public Health. 2020;41:289-308. https://doi.org/10.1146/ annurev-publhealth-040119-094211.

7. Van Natta M, Burke NJ, Yen IH, Fleming MD, Hanssmann CL, Rasidjan MP, et al. Stratified citizenship, stratified health: examining Latinx legal status in the US. healthcare safety net. Soc Sci Med. 2019;220:49-55. https://doi.org/10.1016/j.socscimed.2018.10.024.

8. Young M-EDT, Pebley AR. Legal status, time in the USA, and the well-being of Latinos in Los Angeles. J Urban Health Bull N Y Acad Med. 2017;94:764-75. https://doi.org/10.1007/ s11524-017-0197-3

9. Ortega AN, McKenna RM, Pintor JK, Langellier BA, Roby DH, Pourat N, et al. Health care access and physical and behavioral health among undocumented Latinos in California. Med Care Wolters Kluwer Health. 2018;56:919. https://doi.org/10.1097/ MLR.0000000000000985.

10. Yoona Cho E 2019 Attempts to cancel DACA produce negative effects on health. BIMI-HIFIS Policy Brief Series. 2019. Available from: http://link.springer.com/https://doi.org/10.1007/s10903016-0354-x. Accessed 28 Oct 2021.

11. Wen M, Maloney TN. Neighborhood socioeconomic status and BMI differences by immigrant and legal status: Evidence from Utah. Econ Hum Biol. 2014;12:120-31. https://doi.org/10.1016/j. ehb.2013.03.008.

12. Perreira KM, Pedroza JM. Policies of exclusion: Implications for the health of immigrants and their children. Annu Rev Public Health. 2019;40:147-66. https://doi.org/10.1146/annurev-publh ealth-040218-044115.

13. Benjamins MR, Hummer RA, Eberstein IW, Nam CB. Selfreported health and adult mortality risk: an analysis of causespecific mortality. Soc Sci Med. 1982;2004(59):1297-306. https:// doi.org/10.1016/j.socscimed.2003.01.001.

14. Wu S, Wang R, Zhao Y, Ma X, Wu M, Yan X, et al. The relationship between self-rated health and objective health status: a population-based study. BMC Public Health. 2013;13:320. https:// doi.org/10.1186/1471-2458-13-320.

15. La Parra-Casado D, Stornes P, Solheim EF. Self-rated health and wellbeing among the working-age immigrant population in Western Europe: findings from the European social survey (2014) special module on the social determinants of health. Eur J Public Health. 2017;27:40-6. https://doi.org/10.1093/eurpub/ckw22.

16. Latham K, Peek CW. Self-rated health and morbidity onset among late midlife US. adults. J Gerontol B Psychol Sci Soc Sci. 2013;68:107-16. https://doi.org/10.1093/geronb/gbs104.

17. Idler EL, Benyamini Y. Self-rated health and mortality: a review of twenty-seven community studies. J Health Soc Behav. 1997;38:21-37.

18. Velasco-Mondragon E, Jimenez A, Palladino-Davis AG, Davis D, Escamilla-Cejudo JA. Hispanic health in the USA: a scoping review of the literature. Public Health Rev. 2016;37:31. https:// doi.org/10.1186/s40985-016-0043-2.

19. Lommel LL, Thompson L, Chen J-L, Waters C, Carrico A. Acculturation, inflammation, and self-rated health in Mexican American 
immigrants. J Immigr Minor Health. 2019;21:1052-60. https:// doi.org/10.1007/s10903-018-0805-7.

20. Novak NL, Geronimus AT, Martinez-Cardoso AM. Change in birth outcomes among infants born to Latina mothers after a major immigration raid. Int J Epidemiol. 2017;46:839-49. https://doi. org/10.1093/ije/dyw346.

21. Toomey RB, Umaña-Taylor AJ, Williams DR, Harvey-Mendoza E, Jahromi LB, Updegraff KA. Impact of Arizona's SB 1070 immigration law on utilization of health care and public assistance among Mexican-origin adolescent mothers and their mother figures. Am J Public Health. 2014;104(Suppl 1):S28-34. https:// doi.org/10.2105/AJPH.2013.301655.

22. Martínez AD, Ruelas L, Granger DA. Household fear of deportation in relation to chronic stressors and salivary proinflammatory cytokines in Mexican-origin families post-SB 1070. SSM - Popul Health. 2018;5:188-200. https://doi.org/10.1016/j.ssmph.2018.06.003.

23. Artiga S, Diaz M 2019 Health coverage and care of undocumented immigrants. KFF. 2019. Available from: https://www.kff.org/ racial-equity-and-health-policy/issue-brief/health-coverage-andcare-of-undocumented-immigrants/. Accessed 28 Oct 2021.

24. United States House of Representatives 2022 The Sedition Act of 1798. n.d. Available from: https://history.house.gov/Historical-Highl ights/1700s/The-Sedition-Act-of-1798/. Accessed 27 Jan 2022.

25. Pew Research Center 2015 Chapter 1: The Nation's immigration laws, 1920 to today. 2015. Available from: https://www.pewre search.org/hispanic/2015/09/28/chapter-1-the-nations-immig ration-laws-1920-to-today/. Accessed 27 Jan 2022.

26. Cook J-R 2015 The 1965 Immigration Act that became a law of unintended consequences. Zócalo Public Sq. 2015 Available from: https://www.zocalopublicsquare.org/2015/10/02/the-1965-immig ration-act-that-became-a-law-of-unintended-consequences/events/ the-takeaway/. Accessed 27 Jan 2022.

27. Immigration and Ethnic History Society 2019 Illegal Immigration Reform and Immigrant Responsibility Act (IIRIRA) (1996). 2019. Available from: https://immigrationhistory.org/item/1996-illegalimmigration-reform-and-immigrant-responsibility-act/. Accessed 27 Jan 2022.

28. Nixon R, Qiu L 2018 What Is ICE and why do critics want to abolish it? N Y Times. 2018 Jul 3. Available from: https://www.nytim es.com/2018/07/03/us/politics/fact-check-ice-immigration-aboli sh.html. Accessed 27 Jan 2022

29. Gill H 2018 The Latino Migration Experience in North Carolina, Revised and Expanded Second Edition [Internet]. 2nd ed. Chapel Hill, NC: UNC Press; 2018. Available from: https://uncpress.org/ book/9781469646411/the-latino-migration-experience-in-north-carol ina-revised-and-expanded-second-edition/. Accessed 27 Jan 2022.

30. Carpio G 2019 America's long history of anti-immigrant sentiment and the policing of movement. UC Press Blog. 2019. Available from: https://www.ucpress.edu/blog/43467/americas-longhistory-of-anti-immigrant-sentiment-and-policing-of-movement/. Accessed 27 Jan 2022.

31. Rincon S 2021 The Anti-Immigrant Movement in the United States. Pardee Atlas J. Glob. Aff. 2021. Available from: https:// sites.bu.edu/pardeeatlas/news/the-anti-immigrant-movement-inthe-united-states/. Accessed 27 Jan 2022.

32. Legal Services of Southern Piedmont 2018 North Carolina health insurance eligibility for immigrants. 2018. Available from: https:// www.ncjustice.org/wp-content/uploads/2018/11/Immigrant-Eligi bility-Insurance-Brochure-LSSP-NCJC.pdf. Accessed 27 Jan 2022.

33. NC Department of Transportation 2018 Official NCDMV: Proving legal presence in the U.S. 2018. Available from: https://www. ncdot.gov/dmv/help/Pages/NCDOT. Accessed 27 Jan 2022.
34. Higher Ed Immigration Portal. North Carolina - Data on immigrant students 2022 Pres. Alliance. 2022. Available from: https:// www.higheredimmigrationportal.org/state/north-carolina/. Accessed 27 Jan 2022.

35. Cabral J, Cuevas AG. Health inequities among Latinos/Hispanics: documentation status as a determinant of health. J Racial Ethn Health Disparities. 2020;7:874-9. https://doi.org/10.1007/ s40615-020-00710-0.

36. Djuric Z, Bird CE, Furumoto-Dawson A, Rauscher GH, Ruffin MTTH, Stowe RP, et al. Biomarkers of Psychological Stress in Health Disparities Research. Open Biomark J. 2008;1:7-19. https://doi.org/10.2174/1875318300801010007.

37. Tuggle AC, Cohen JH, Crews DE. Stress, migration, and allostatic load: a model based on Mexican migrants in Columbus. Ohio J Physiol Anthropol. 2018;37:2801. https://doi.org/10.1186/ s40101-018-0188-4.

38. Mitchell CM 2022 Hidden in America: A Qualitative analysis of undocumented Hispanics' lived experiences. [United States -Delaware]: Wilmington University (Delaware). Available from: https://www.proquest.com/docview/1427858697/abstract/51160 70A08544A16PQ/1. Accessed 27 Jan 2022.

39. Cervantes RC, Fisher DG, Padilla AM, Napper LE. The Hispanic Stress Inventory Version 2: improving the assessment of acculturation stress. Psychol Assess. 2016;28:509-22. https://doi.org/ 10.1037/pas0000200.

40. Ortega AN, Rodriguez HP, Vargas BA. Policy dilemmas in Latino health care and implementation of the Affordable Care Act. Annu Rev Public Health. 2015;36:525-44. https://doi.org/10.1146/annur ev-publhealth-031914-122421.

41. Vargas Bustamante A, Fang H, Garza J, Carter-Pokras O, Wallace SP, Rizzo JA, et al. Variations in healthcare access and utilization among Mexican immigrants: the role of documentation status. J Immigr Minor Health. 2012;14:146-55. https://doi.org/10.1007/ s10903-010-9406-9421.

42. Philbin MM, Flake M, Hatzenbuehler ML, Hirsch JS. State-level immigration and immigrant-focused policies as drivers of Latino health disparities in the United States. Soc Sci Med. 1982;2018(199):29-38. https://doi.org/10.1016/j.socscimed.2017.04.007.

43. Artiga S, Ubri P 2017 Living in an immigrant family in America: how fear and toxic stress are affecting daily life, wellbeing, \& health. KFF. 2017. Available from: https://www. kff.org/racial-equity-and-health-policy/issue-brief/living-inan-immigrant-family-in-america-how-fear-and-toxic-stressare-affecting-daily-life-well-being-health/. Accessed 28 Oct 2021.

44. Jawetz T, Svajlenka NP 2017 Thousands of DACA recipients are already losing their protection from deportation. Center for American Progress. 2017. Available from: https://www.ameri canprogress.org/issues/immigration/news/2017/11/09/442502/ thousands-daca-recipients-already-losing-protection-deportation/. Accessed 28 Oct 2021.

45. Congressional Research Services 2021 The Trump Administrations "Zero Tolerance" immigration enforcement policy. 2021. Available from: https://sgp.fas.org/crs/homesec/R45266.pdf. Accessed 25 Jan 2022.

46. Capps R, Koball H, Campetella A, Perreira K, Hooker S, Pedroza JM 2015 Implications of immigration enforcement activities for the well-being of children in immigrant families. Migration Policy Institute; 2015. Available from: https://www.migrationpolicy.org/ research/implications-immigration-enforcement-activities-wellbeing-children-immigrant-families. Accessed 28 Oct 2021. 
47. Department of Homeland Security. Temporary Protected Status. 2018. Available from: https://www.uscis.gov/humanitarian/tempo rary-protected-status. Accessed 28 Oct 2021.

48. Center for Migration Studies 2021 President Trump's Executive Orders on immigration and refugees. 2021. Available from: https://cmsny.org/trumps-executive-orders-immigration-refugees/. Accessed 28 Oct 2021.

49. Lopez WD, Kruger DJ, Delva J, Llanes M, Ledón C, Waller A, et al. Health implications of an immigration raid: Findings from a Latino community in the Midwestern United States. J Immigr Minor Health. 2017;19:702-8.

50. Capps R, Gelatt J, Greenberg M 2020 The public-charge rule: broad impacts, but few will be denied green cards based on actual benefits use. Migration Policy Institute. 2020. Available from: https://www.migrationpolicy.org/news/public-charge-denialgreen-cards-benefits-use. Accessed 28 Oct 2021.

51. Haley J, Kenney J, Bernstein H, Gonzalez D 2020 One in five adults in immigrant families with children reported chilling effects on public benefit receipt in 2019. Urban Institute. 2020. Available from: https://www.urban.org/research/publi cation/one-five-adults-immigrant-families-children-reportedchilling-effects-public-benefit-receipt-2019. Accessed 28 Oct 2021.

52. Despres C 20208 big questions for Latinos on the new Public Charge Rules and immigration. Salud America. 2020. Available from: https://salud-america.org/8-big-questions-new-publiccharge-immigration-latinos/. Accessed 28 Oct 2021.

53. Yu M, Kelley AT, Morgan AU, Duong A, Mahajan A, Gipson JD. Challenges for adult undocumented immigrants in accessing primary care: a qualitative study of health care workers in Los Angeles County. Health Equity. 2020;4:366. https://doi.org/10. 1089/heq.2020.0036.

54. Callaghan T, Washburn DJ, Nimmons K, Duchicela D, Gurram A, Burdine J. Immigrant health access in Texas: Policy, rhetoric, and fear in the Trump era. BMC Health Serv Res. 2019;19:342. https://doi.org/10.1186/s12913-019-4167-1.

55. Held ML, Nulu S, Faulkner M, Gerlach B. Climate of fear: Provider perceptions of Latinx immigrant service utilization. J Racial Ethn Health Disparities. 2020;7:901-12. https://doi.org/10.1007/ s40615-020-00714-w.

56. Fleming PJ, Lopez WD, Mesa H, Rion R, Rabinowitz E, Bryce $\mathrm{R}$, et al. A qualitative study on the impact of the 2016 US election on the health of immigrant families in Southeast Michigan. BMC Public Health. 2019;19:947. https://doi.org/10.1186/ s12889-019-7290-3.

57. Cholera R, Ranapurwala SI, Linton J, Shmuel S, Miller-Fitzwater A, Best DL, et al. Health care use among Latinx children After 2017 Executive Actions on immigration. Pediatrics. 2021;147:e20200272. https://doi.org/10.1542/peds.2020-0272.

58. Pintor JK, Call KT 2019 State-Level immigrant prenatal health care policy and inequities in health insurance among children in mixed-status families. Glob Pediatr Health. 6. https://doi.org/10. 1177/2333794X19873535

59. Doshi M, Lopez WD, Mesa H, Bryce R, Rabinowitz E, Rion $\mathrm{R}$, et al. Barriers \& facilitators to healthcare and social services among undocumented Latino(a)/Latinx immigrant clients: perspectives from frontline service providers in Southeast Michigan. PLOS ONE Public Library of Science. 2020;15:e0233839. https:// doi.org/10.1371/journal.pone.0233839.

60. Rhodes SD, Mann L, Simán FM, Song E, Alonzo J, Downs M, et al. The impact of local immigration enforcement policies on the health of immigrant Hispanics/Latinos in the United States.
Am J Public Health American Public Health Association. 2015;105:329. https://doi.org/10.2105/AJPH.2014.302218.

61. Young M-EDT, Madrigal DS. Documenting legal status: a systematic review of measurement of undocumented status in health research. Public Health Rev. 2017;38:26. https://doi.org/10.1186/ s40985-017-0073-4.

62. Hays RD, Bjorner JB, Revicki DA, Spritzer KL, Cella D. Development of physical and mental health summary scores from the patient-reported outcomes measurement information system (PROMIS) global items. Qual Life Res Int J Qual Life Asp Treat Care Rehabil. 2009;18:873-80. https://doi.org/10.1007/ s11136-009-9496-9.

63. Marin G, Gamba RJ. A new measurement of acculturation for Hispanics: The Bidimensional Acculturation Scale for Hispanics (BAS). Hisp J Behav Sci. 1996;18:297-316. https://doi.org/10. 1177/07399863960183002.

64. Sabogal F, Marín G, Otero-Sabogal R, Marín BV, Perez-Stable EJ. Hispanic familism and acculturation: what changes and what doesn't? Hisp J Behav Sci. 1987;9:397-412. https://doi.org/10. 1177/07399863870094003.

65. Berkman LF, Glass T, Brissette I, Seeman TE. From social integration to health: Durkheim in the new millennium. Soc Sci Med. 1982;2000(51):843-57. https://doi.org/10.1016/s0277-9536(00) 00065-4.

66. Perez RM, Araujo Dawson B, Suárez-Orozco C. Understanding acculturation, depressive symptoms, and the protective role of family involvement among Latino(a) immigrant families. J Fam Soc Work. 2011;14:429-45. https://doi.org/10.1080/10522158. 2011.617030.

67. Hastie T, Qian J. Glmnet Vignette. 2016. Available from: https:// web.stanford.edu/ hastie/glmnet/glmnet_beta.html. Accessed 28 Oct 2021.

68. Torres JM, Wallace SP. Migration circumstances, psychological distress, and self-rated physical health for Latino immigrants in the United States. Am J Public Health. 2013;103:1619-27. https:// doi.org/10.2105/AJPH.2012.301195.

69. Iten AE, Jacobs EA, Lahiff M, Fernández A. Undocumented immigration status and diabetes care among Mexican immigrants in two immigration "sanctuary" areas. J Immigr Minor Health. 2014;16:229-38. https://doi.org/10.1007/ s10903-012-9741-0.

70. Vie TL, Hufthammer KO, Meland E, Breidablik HJ. Self-rated health (SRH) in young people and causes of death and mortality in young adulthood A prospective registry-based Norwegian HUNT-study. SSM - Popul Health. 2019;7:100364. https://doi. org/10.1016/j.ssmph.2019.100364.

71. McClure HH, Snodgrass JJ, Martinez CR Jr, Eddy JM, Jiménez RA, et al. Discrimination, psychosocial stress, and health among Latin American immigrants in Oregon. Am J Hum Biol. 2010;22:421. https://doi.org/10.1002/ajhb.21002.

72. Zajacova A, Huzurbazar S, Todd M. Gender and the structure of self-rated health across the adult life span. Soc Sci Med. 2017;187:58-66. https://doi.org/10.1016/j.socscimed.2017.06. 019.

73. Bacong A, Sohn H 2020 Disentangling contributions of demographic, family, and socioeconomic factors on associations of immigration status and health in the United States. J Epidemiol Community Health. 2020; jech-2020-214245. https://doi.org/10. 1136/jech-2020-214245

74. Carmel S 2019 Health and well-being in late life: Gender differences worldwide. Front Med. 2019. Available from: https://www. frontiersin.org/article/https://doi.org/10.3389/fmed.2019.00218. Access 26 Jan 2022. 
75. Parast L, Mathews M, Martino S, Lehrman WG, Stark D, Elliott MN. Racial/ethnic differences in emergency department utilization and experience. J Gen Intern Med. 2021. https://doi.org/10. 1007/s11606-021-06738-0.

76. Ackert E, Hong SH, Martinez J, Van Praag G, Aristizabal P, Crosnoe R. Understanding the health landscapes where Latinx immigrants establish residence in the US. Health Aff. 2021;40:110816. https://doi.org/10.1377/hlthaff.2021.00176.
77. Ohrnberger J, Fichera E, Sutton M. The relationship between physical and mental health: a mediation analysis. Soc Sci Med. 2017;195:42-9. https://doi.org/10.1016/j.socscimed.2017.11.008.

Publisher's Note Springer Nature remains neutral with regard to jurisdictional claims in published maps and institutional affiliations.

\section{Authors and Affiliations}

\section{Allison McCord Stafford ${ }^{1}$ (I) - Aneri Tanna ${ }^{2} \cdot$ Karina Moreno Bueno $^{2} \cdot$ Gabriela A. Nagy $^{1,3} \cdot$ Irene Crabtree Felsman $^{1,4}$. Scott de Marchi ${ }^{5} \cdot$ Rushina Cholera $^{6} \cdot$ Kate Evans $^{7} \cdot$ Eliazar Posada $^{8} \cdot$ Rosa Gonzalez-Guarda $^{1}$}

Aneri Tanna

aneri.tanna@duke.edu

Karina Moreno Bueno

karina.moreno.bueno@duke.edu

Gabriela A. Nagy

gabriela.nagy@duke.edu

Irene Crabtree Felsman

irene.felsman@duke.edu

Scott de Marchi

demarchi@duke.edu

Rushina Cholera

rushina.cholera@duke.edu

Kate Evans

evans@law.duke.edu

Eliazar Posada

eliazar@posadastrategies.com

Rosa Gonzalez-Guarda

rosa.gonzalez-guarda@duke.edu
Duke University School of Nursing, 307 Trent Dr. DUMC 3322, Durham, NC 27710, USA

2 Trinity College of Arts and Sciences, Duke University, Box 90046, Durham, NC 27710, USA

3 Department of Psychiatry and Behavioral Sciences, Duke University Medical Center, 2213 Elba St, Durham, NC 27705, USA

4 Duke Global Health Institute, Duke University, 310 Trent Dr, Durham, NC 27710, USA

5 Department of Political Science, Duke University, 140 Science Dr, Durham, NC 27708, USA

6 Department of Pediatrics, Duke University School of Medicine, 2301 Erwin Rd, Durham, NC 27707, USA

7 Duke University School of Law, 210 Science Dr, Durham, NC 27708, USA

8 El Centro Hispano Inc, 2000 Chapel Hill Rd, Durham, NC 27707, USA 